\title{
IMPROVED MODEL OF VIBRATORY DAMPED GLASS REINFORCED PLASTIC (GRP)
}

\author{
Ahmed Maher,* and Fawkia Ramadan** \\ * Prof. of Applied mechanics. Production and Mechanical Design \\ Department, Faculty of Engineering, Minufiya University, \\ Shebin El-Kom Egypt. \\ ** Lecturer Production and Mechanical Design Department, \\ Façulty of Engineering, \\ Minufiya University, Shebin El-Kom Egypt
}

\begin{abstract}
An improved model of modal parameters of glass reinforced plastic structures (GRP) is presented. The extensive analysis of the fitted experimental results proves that the quasi uniform mass damping is the main feature of vibratory GRP structures. Consistent with the analysis it is stated that the number of boundary degrees of freedom, code number, volume fraction and typical order of natural mode have significant effects respectively on controlling the type of each set of quasi rectangular hyperbolic relations associated with the vibration damping of GRP structures.
\end{abstract}

The close agreement between the numerical results of the finite element model and the fitted experimental results shows the efficiency and applicability of the present modelling techniques, resulting in significant simplifications in solutions of idiosyncratic composite systems with lowest residual errors.

\section{INTRODUCTION :}

Model updating has been a subject of study in literature for many years $[1,2]$. Most of the procedures try to minimize the deviation between the analytical and experimental models by adjusting the analytical and experimental model on the basis of experimental measurements. The development of mathematical models has required best memory to be more accurate and has high computational speed which plays an important role in vibration analysis of composite complex structures in the recent decades.

Manuscript received from Dr .Fawkia Ramadan

Accepted on : $9 / 6 / 2001$

Engineering Research Journal Vol 24,No 3, 2001 Minufiya University, Faculty Of

Engineering, Shebien El-Kom, Egypt, ISSN 1110-1180 
At the present time, it is still difficult to determine accurately the model characteristics of composite structures particularly the damping capacity by an analytical approach. The experimental confirmation prediction is therefore at very least desirable and can be used to build up the mathematical model. This in turn leads to more clearly understand the effect of parameters for controlling the dynamic nature of composite complex structure.

In the present work, an attempt has been made to build up an efficient simulation of modal parameters with an improvement of convergence characteristics of modelling process within a wide range of frequencies for different stacking sequences at two levels of volume fraction taking into account the influences of constraints subjected to the composite structural beams.

For the sake of minimization the residual errors and raising the confidence levels for building up the model, weight factors $(\alpha, a)$ have been introduced for correlating and updating the construction of the mathematical model to the experimental data through the utilization of the curve fitting response functions [3].

This has resulted generalized quasi rectangular hyperbolic relationships between the loss factors and the natural frequencies for various degrees of constraints within the confidence level $99.2 \%$ at least. This in turn permits the uncoupling of simultaneous equations of motion of composite structures of large number of degrees of freedom with the lowest residual errors.

In that way the curvilinear fitting techniques are reutilized to generate other quasi hyperbolic relationships concerned with the loss factors in various set of natural modes with confidence level $98.6 \%$ at least.

Other object of the present work is to analyze quantitatively the influences of the degree of constraints, to be considered, on the nature of modal parameters of composite structures.

In the experimental work, Fig. (1b), four types of boundary conditions have been subjected to composite beams made from glass reinforced plastic GRP. Various specimens made from three plies ( $L$ X b X t) Fig. (1a), are tested for two levels of volume fraction (a) a weakly composite $15 \%$ and (b) an average composite $45 \%$ in each type of constraints.

Experimentally the first four natural frequencies and the corresponding loss factors are listed in the third and fourth columns in tables 1 to 8 , respectively... For the sake of verification with the experimental measurements the first four natural frequencies at two levels of volume fraction are computed by the use of the modified formula MFM [3] and listed in the second column of these tables.

To high light the nature of the damping parameters, family of curves representing mutual relationships of modal parameters are plotted in Figs. $(2 \& 3)$ in terms of the results listed in Tables ( 1 to 8 ). 
The close agreement of the results of the proposed mathematical and experimental models proves the efficient applicability of the proposed model and enriches the understanding of dynamic nature of vibrating damping composite structures. This in turn leads to uncoupling the dynamic equations of motion particularly of large complex composite structures with minimum time of computation and residual errors.

\section{MATHEMATICAL MODEL OF VIBRATION DAMPING OF COMPOSITE STRUCTURAL BEAM}

In the last decade, it was mentioned in Ref. [5] that the hyperbolic relations between $\eta$ and $\omega$ of composite plates, vibrating at the first mode and subjected to different boundary conditions, provide a more reliable prediction throughout the utilization of the uniform mass damping model. The developed mathematical model was established by the utilization of the student distribution approximation with confidence level at $95 \%$.

To improve the convergence characteristics of the mathematical model within a wide range of frequency spectrum at various code numbers, modified quasi hyperbolic relations are developed by introducing the proper weight factors ( $\alpha, a)$, [3] throughout utilization of the least square technique.

In the present work a generalized vibratory damped model made from glass reinforced plastic is developed. The interrelations between the loss factors and the natural frequencies from one side and the order of natural modes from the other side are obtained by applying the fitting response function on the experimental results of composite structural beam specimens. The models are subjected to different types of boundary conditions, for various stacking sequences, and for two levels of volume fraction. As stated in [3] the quasi rectangular hyperbolic relations between loss factors $\eta$ and natural frequencies $\omega$ are recast as

$$
\eta_{i}=a_{i}\left(\omega_{i}\right)^{-\alpha i} \quad i=1,2, \ldots n
$$

In addition the same relations between loss factor $\eta$ and order of natural modes (i) is deduced by the same technique and the form

$$
\eta_{i}=B_{i}(i)^{-\beta i} . \quad i=1,2, \ldots n
$$

where $n=$ the number of natural frequencies in the selected frequency spectrum.

With the help of logarithm forms these relations can be transferred to linear forms here as.

$$
l_{n} \eta_{i}+\alpha_{i} l_{n} \omega_{i}=l_{n} a_{i}
$$




$$
l_{n} \eta_{i}+\beta_{i} l_{n}(i)=l_{n} B_{i} \text { for } i=1,2, \ldots r
$$

The advantages of logarithm form is mainly for facilitation the quantitative analysis and the applications of extrapolation and interpolation techniques for controlling the loss factors and frequencies at the selected boundary conditions within the required frequency spectrum.

For the sake of verification of the measured natural frequencies at various states, the first four natural frequencies were numerically computed by the modified developed formula [4] and the form

$$
\omega_{i}=\frac{\lambda_{i}}{2 \Pi L^{2}}\left(\frac{D^{*}}{\rho_{c} \cdot t}\right)^{\frac{1}{2}}
$$

where $\mathrm{D}^{*}=$ the condensed bending stiffness modulus of composite structural beam,

$\rho_{\mathrm{c}}=$ the equivalent specific mass of composite beam [3].

\section{EXPERIMENTAL MODEL OF VIBRATION DMPING O F COMPOSITE STRUCTURAL BEAM}

\subsection{Experimental specimens :}

The frequency response tests were performed on four types of fixation on composite beams made from three layers glass fiber reinforced plastic GRP of various orientations at the first four modes and at two level of volume fractions. A typical specimens GRP composite beam of dimension $(210 \times 20 \times 3 \mathrm{~mm})$ made of three plies with $1 \mathrm{~mm}$ thickness for each ply for $V_{\mathrm{f}} 15 \%$ and $V_{f}$ $45 \%$ is shown in Fig. (1a). To study the effects of degree of constraint, lamina orientations and stacking sequences on the modal parameters, six code numbers of specimens were fabricated by hand lay up technique and stated as $(0 / 0 / 0),(0 / 30 / 0),(0 / 45 / 0)$, $(0 / 90 / 0),(45 /-45 / 0)$ and $(45 / 0 / 45)$ for the two volume fraction 15 $\%$ and $45 \%$.

\subsection{Instrumentation Layout :}

The experimental apparatus is shown in Fig. (1b). The four boundary conditions of the six specimens stated as fixed-free (3D), hinged - hinged (4D), fixed-hinged (5D), and fixed-fixed (6D) could be maintained by the clamping fixture.

The specimens are excited by impact hammer to determine the resonance frequency [6]. The excitation signal is fed to the dual channel analyzer through conditioning amplifier and a light weight accelerometer.

Signal analysis is carried out by the analyzer linked to a computer with structure measurement system as shown in Fig. (1b). The analyzer having a frequency range of $25 \mathrm{KHz}$ can zoom in various selected frequency ranges. 
The damping parameters for each specimen are calculated by using the peak method within the selected frequency spectrum.

\section{RESULTS AND DISCUSSIONS :}

Refer to [3] the least square technique is utilized and the quasi rectangular hyperbolic curve fitting is plotted for the measured values $\left(\eta_{i}, \omega_{i}\right)$ within the ranged of confidence level $98 \%$ to $99.99 \%$ as shown in Figs. $(2,3$,).

To study the effects of the number of boundary degrees of freedom stated as 3D, 4D, 5D and 6D on the damping capacity of the samples, Fig. (2) indicates that the damping capacities increase and the natural frequencies decrease in monotonically manner with increasing degrees of freedoms.

Without loss the generality the quasi hyperbolic interrelations of damped natural frequencies $\omega_{\mathrm{d}}$ and damping capacities are permanently valied for the four cases of boundary conditions subjected to the six specimen lamina orientations for the first four modes, and for the two volume of fractions $V_{f}$ as depicted in Figs. (2 and 3 ) and the form

$\eta_{\mathrm{i}}=\mathrm{a}\left(\omega_{\mathrm{i}}\right)^{-\alpha}$ for $\mathrm{i}=1,2,3,4(1>\alpha>0, \mathrm{a}>0)$

With the help of the least square technique concerned with the curve fitting response functions, the generalized quasi hyperbolic quantitative relations between damping capacities ( $\eta_{\mathrm{av}}$ ) and frequencies $\left(\omega_{\mathrm{av}}\right.$ ) for the various types of fixation at the two volume fraction are correlated with confidence level $98.4 \%$, at least, as listed in Table (9) and plotted in Figs. (4a and 4b).

To facilitate the quantitative analysis of the weight factors $(\alpha$, a) for updating the mathematical model logarithmic forms of the quasihyperbolic relations $\left(\eta_{i}-\omega_{i}\right)$, for various orientations and for different types of fixation for all specimens are plotted in linear forms as represented in Figs. $(5 \& 6)$ and $(7 \& 8)$. It is noticed that the slopes assigned by the weight factor $(\alpha)$ are mainly depending on the degree of isotropical state while the damping constant (a) depends mainly on the flexibility of the specimens.

From the computational and experimental values depicted in the previous tables and figures it is shown that the weight factors increase as the volume fraction increases and as the lamina orientation leading to a low stiff composite structural beams as expected.

Also it is shown that boundary conditions (types of fixation) have significant effects on the damping parameters associated with the weight factors $(\alpha, a)$ compared either with the influences of lamina 
orientations or with the volume fraction $V_{f}$. As an example the damping constant in the fixed free state is increased by about 24 times of the correspondant in the fixed fixed state as shown in Table (9).

Table (9) : Gencralized forms of interrelations between damping capacities, $\eta$ and natural frequencies, $w$ for various fixations of LCB at two levls of fiber volume fractions. $V_{i}=15 \%$ and $45 \%$. (Ref. Tubles 1 to 4 for $V_{i}=15 \%$ and Tables 5 to 8 for $\left.v_{1}=45 \%\right)$

\begin{tabular}{|c|c|c|}
\hline \multirow{2}{*}{ Pixalion } & \multicolumn{2}{|c|}{ Fiber volume fraction, $\mathrm{Vf}$} \\
\hline & $15 \%$ & $45 \%$ \\
\hline & $\begin{array}{l}\eta_{i}=3.097479503\left(\omega_{i}\right)^{-0.56 .37788911} \\
\text { confidence level }=98.79 \%\end{array}$ & $\eta_{i}=2.852583936\left(\omega_{i}\right)^{-0.5567207156}$ \\
\hline & $\eta_{i}=13.67496044\left(\omega_{i}\right)^{-(0.7156483416}$ & $\eta_{i}=12.48529197\left(\omega_{i}\right)^{-0.7(1) 4(1) 7.4391}$ \\
\hline & $\begin{array}{l}\eta_{i}=31.375641\left(\omega_{i}\right)^{-0.7967 .30281} \\
\text { Conlidence level }=98.75 \%\end{array}$ & $\begin{array}{l}\eta_{\mathrm{i}}=26.87749517\left(\omega_{\mathrm{i}}\right)^{-0.7792277878} \\
\text { Confidence level }=98.90 \%\end{array}$ \\
\hline & $\begin{array}{l}\eta_{\mathrm{i}}=74.56746475\left(\omega_{\mathrm{i}}\right)^{-(0.8867 .527246} \\
\text { Confidence level }=98.40 \%\end{array}$ & $\begin{array}{l}\eta_{i}=63.95389482\left(\omega_{i}\right)^{-(1) .8660+4+403+4} \\
\text { Confidence level }=98.46 \%\end{array}$ \\
\hline
\end{tabular}

In view of the experimental measurements listed in Tables 1 to 8 it is obvious that the loss factors are monotonically decrease in hyperbolic feature as the mode number increases.

For quantitative estimation of these relations, the curve fitting response techniques is utilized and the form

$\eta_{i}=B(i)^{-1.4}$ for $i=1,2,3,4$

It is of interesting to note that the loss factors decrease by the same rate by about 1.4 for all cases while the damping constants $B$; are strongly affected by the volume fraction.

By visual inspection of the measured values of loss factors and the corresponding hyperbolic fitting relations in Tables 1 to 8 it is noticed that the damping constant $B$ is nearly equal to the loss factor of the first natural mode. This remark exists for all types of fixations and for various code number such that one can suggest that the loss factor at any number of mode can be related to the correspond 1 st mode in the following empirical serial form.

$$
\eta_{i}=\eta_{1}(i)^{-1.4} i=2,3 \ldots n
$$

The correspond logarithmic form is then given by

$$
l_{n} \eta_{i}+1.4 l_{n} i=l_{n} \eta_{1}
$$

and as shown in Fig. (9). 
Figs. (10) and (11) show the quasilinear relations between the number of degrees of boundary freedom and the equivalent damping loss factor for the two levels of volume fractions.

It is worth to mention here that the use of logarithmic form is not only, for facilitation the quantitative analysis and for computing the loss factors either in terms of the natural frequency or in terms of the mode number by extrapolation or interpolation techniques, but also for control the magnitudes of natural frequencies and damping capacity by proper choice of boundary conditions and types of fixations in the selected range of the frequency spectrum. As an example from the results listed in Tables ( 1 and 4 ) it is noticed that the third natural frequency at $(0 / 30 / 0)$ orientation of the fixed-fixed beam is nearly equal to the fourth natural frequency at $(0 / 30 / 0)$ of the fixed free for $V_{f} 15 \%$.

Similarly the fourth natural frequency at $(0 / 0 / 0)$ orientation of the fixed free beam is nearly equal to the third natural frequency $(0 / 0 / 0)$ at fixed fixed for volume $V_{f} 15 \%$. Also for $V_{f}=45 \%$ at fixed free it is obvious that the third natural frequency at $(0 / 30 / 0)$ is nearly equal to the second natural frequency at the fixed fixed beam and the damping capacities are almost the same.

By the inspection of experimental results listed in Tables ( 1 to 8 ) it is evident that the changes of outer orientations have permenant significant effects on the damping capacity, and stiffness, of the specimens compared with the changes of the inner orientation regardless to the degrees of constraint and of the degrees of isotropism at different mode shapes as stated in [3].

For the sake of verification of measurements of frequencies listed in column three, the modified formula MFM is utilized to compute the first four undamped natural frequencies and listed in the second column of Tables 1 to 8 . The comparison between the numerical results and experimental measurements shows the good agreement and the efficiency of the modified MFM to be utilized for computing the natural frequencies of composite structures with a wide range of frequencies and at different degrees of fixations.

\section{CONCLUSION :}

The present work is focused on the development of a generalized model of vibratory damped glass reinforced plastic (GRP) structures. The analysis of the fitted results of measurements indicates the following conclusion remarks.

1. Without loss the generality the quasi uniform mass damping is the main feature of damping behavior of GRP structures in various states.

2. The families of quasi rectangular hyperbolic relations between the damping loss factors and natural frequencies are stated by the lowest residual errors by using the mathematical fitting 
convenience of the two weight factors $\alpha$ and a.

3. The properties of each family relating loss factors and resonant frequencies are controlled mainly by the following four parameters :

* number of boundary degrees of freedom,

* volume fraction,

* lamina orientations and stacking sequences and

* typical order of natural mode.

In contrast to the limited variations of the weight factor $(\alpha)$, the damping constant (a) is strongly affected by the type of fixation compared with the other controlling parameters as shown in the curves of figures.

4. To disregard the influences of controlling parameters, the logarithmic trend of the uniform mass damping behavior of GRP is characterized by the linear decreasing of loss factors and by nearly constant rate $(\alpha)$ against the monotonic increasing of order of the natural modes.

\section{ACKNOWLEDGEMENTS :}

We would like to express our thanks to $\mathrm{Mr}$. M. Ferra for assistance in preparing the specimens.

\section{REFERENCES :}

[1] Martin W. Trethewey and John A. Cafeo "Design Modification with experimental based structural models" 12th IMAC 1995, $1666-1672$.

[2] Mohamed Kaouk and David Zimmeman "Structural health assessment using A Partition model updating technique 13th IMAC 1995, 1673 - 1686.

[3] Ahmed Maher, Fawkia Ramadan and Mohamd Ferra "Modelling of vibration damping in composite structures Journal of composite structure 46 (1999) 163 - 170.

[4] Blevins R.D. Formula for Natural frequency and Mode shape. Litton Educational publishers, 1979.

15] Ahmed Maher, Evaluative eigen analysis of composite structures J. Comp Structure 1994, 29: 191 - 195.

[6] R.B. Randall. "Application of B, K Equipment to Frequency Analysis" Naerum offest Tryk, Naerm, Denmark.

NOMENCLATURE :

$\mathrm{V}_{\mathrm{f}} \quad$ Volume fraction GRP Glass reinforced plastic

i Mode number

$\alpha$, a, B. $\beta$ weight factor" $\eta$ Damping loss factor

$\eta_{a v}$. Average damping capacities $\omega_{a v}$. Average natural frequencies 
Table (1) : The numerical and experimental modal paramelers or the first rour
modes of the rixed-free GRP beam of volume fraction is $\%$.

\begin{tabular}{|c|c|c|c|c|c|c|c|}
\hline Thbl & 10101 & & & Tuble 1,4 & $10 / 90$ & 101 & \\
\hline mode No & $\bar{\omega}_{i}$ & $\overline{\omega_{\mathrm{di}}}$ & $7 \%$ & $\operatorname{mode~}_{(i)}$ & $w_{i}$ & $\omega_{d i}$ & 7iक \\
\hline $\begin{array}{l}1 \\
2 \\
3 \\
4\end{array}$ & $\begin{array}{c}211.109 \\
1322.981 \\
3704.384 \\
7259.115\end{array}$ & $\begin{array}{c}188.496 \\
1294.336 \\
3694.513 \\
7250.746\end{array}$ & $\begin{array}{r}13.334 \\
4.370 \\
2.552 \\
2.080\end{array}$ & $\begin{array}{l}1 \\
2 \\
3 \\
4\end{array}$ & $\begin{array}{r}208.482 \\
1306.526 \\
3658.309 \\
7668.825\end{array}$ & $\begin{array}{r}175.920 \\
1231.504 \\
3565.844 \\
6572.212\end{array}$ & {$\left[\begin{array}{c}16.072 \\
5.612 \\
2.228 \\
2.486\end{array}\right]$} \\
\hline 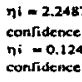 & 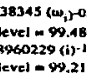 & 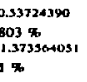 & & $\begin{array}{l}n i-3.0110 \\
\text { confidernce } \\
\eta \mathrm{n}=0.153 \\
\text { confidemic }\end{array}$ & 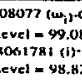 & 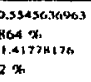 & \\
\hline Tutble 1.2 & $10 / 30$ & & & Tuble i.s & $\mid 451-4:$ & $s(0)]$ & \\
\hline${ }_{\text {(i) }}^{\text {Noce }}$ & $\omega_{i}$ & $\omega_{\mathrm{di}}$ & $\eta_{i} \%$ & maxuse No & $4_{i}$ & $\mathrm{w}_{\mathrm{dit}}$ & $n_{i} x_{0}$ \\
\hline $\begin{array}{l}1 \\
2 \\
3 \\
4\end{array}$ & $\begin{array}{r}209.544 \\
1313.186 \\
3676.958 \\
7205.362\end{array}$ & $\begin{array}{r}185.354 \\
124.351 \\
3606.548 \\
7200.530\end{array}$ & $\mid \begin{array}{c}13.898 \\
4.346 \\
2.614 \\
2.0394\end{array}$ & $\begin{array}{l}1 \\
2 \\
3 \\
4\end{array}$ & $\begin{array}{r}171.160 \\
1072.650 \\
3003.425 \\
5885.510\end{array}$ & $\begin{array}{r}163.363 \\
100-13.004 \\
2978.230 \\
5811.946\end{array}$ & $\begin{array}{r}20.000 \\
6.024 \\
3.794 \\
2.648\end{array}$ \\
\hline $\begin{array}{l}\eta i=2.463 \\
\text { confitence } \\
\eta i=0.13 \\
\text { confidence }\end{array}$ & 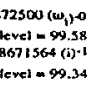 & 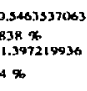 & & $\begin{array}{l}\eta i-3.5631 \\
\text { confiutence } \\
\eta i=0.187 \\
\text { confistence }\end{array}$ & 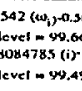 & 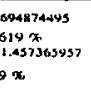 & \\
\hline Teble 1.3 & $10 / 45$ & & & Twtie 1.6 & $\{4510$ & 453 & \\
\hline $\begin{array}{c}\text { mode No } \\
\text { (i) }\end{array}$ & $\omega_{i}$ & andi & niक & $\begin{array}{c}\operatorname{mox} \times 1 \mathrm{No} \\
\text { (i) }\end{array}$ & $\overline{\omega_{i}}$ & ${ }_{1 \mathrm{Sl}_{i}}$ & $n_{i} x_{0}$ \\
\hline $\begin{array}{l}1 \\
2\end{array}$ & $\begin{array}{r}208.930 \\
1307.506\end{array}$ & $\begin{array}{r}179.071 \\
1237.788\end{array}$ & $\left|\begin{array}{c}14.912 \\
6.076\end{array}\right|$ & $\begin{array}{l}1 \\
7\end{array}$ & $\begin{array}{l}123.615 \\
774.0616\end{array}$ & $\begin{array}{l}119.381 \\
760.549\end{array}$ & $\left|\begin{array}{r}23.684 \\
8.146\end{array}\right|$ \\
\hline 3 & 3661.049 & 3581.416 & 2.632 & 3 & 2169.054 & 2161.416 & 4.534 \\
\hline 4 & 7174.191 & 6754.474 & 2.280 & 4 & 4250.536 & 4234.867 & $3.0 \times 6$ \\
\hline $\begin{array}{l}n i-2.7436 \\
\text { comfidence } \\
n i=0.14 i \\
\text { confidence }\end{array}$ & 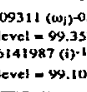 & 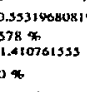 & & 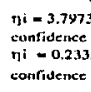 & 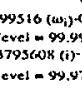 & 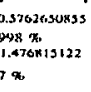 & \\
\hline
\end{tabular}

Table (2) : The numerical and experimental modal parameters of the fisst four

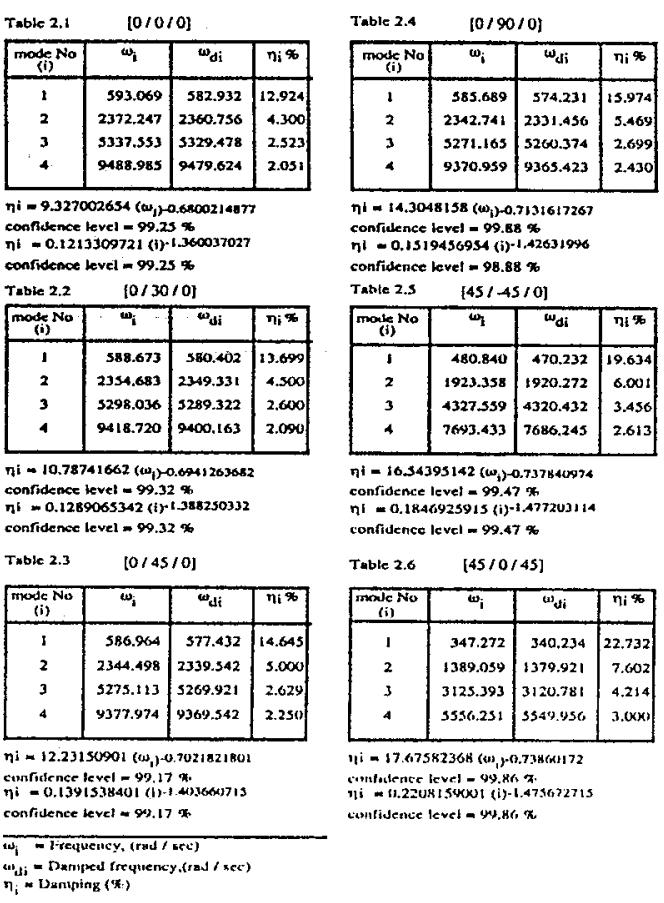

Table (3) : The numerical and experimental modal parameters or the first four
modes of the gixed-hinged GRP beam of volume fraction is $\%$

\begin{tabular}{|c|c|c|c|}
\hline $\operatorname{mode~}_{(i)}$ & $\omega_{i}$ & $\omega_{d i}$ & $n \pi x$ \\
\hline $\begin{array}{l}1 \\
2 \\
3 \\
4\end{array}$ & $\begin{array}{c}925.742 \\
2989.939 \\
6259.172 \\
10703.536\end{array}$ & $\mid \begin{array}{c}918.733 \\
2960.321 \\
6240.411 \\
10694.240\end{array}$ & $\begin{array}{r}12.756 \\
4.267 \\
2.489 \\
2.020\end{array}$ \\
\hline \multicolumn{4}{|c|}{ 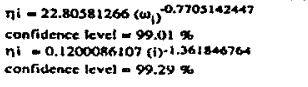 } \\
\hline Tosle 3.2 & \multicolumn{3}{|c|}{$80 / 30 \% 01$} \\
\hline${ }_{(i)}^{\text {mode }}$ & $\omega_{i}$ & $\omega_{\mathrm{di}}$ & $\eta_{i} \infty$ \\
\hline $\begin{array}{l}1 \\
2 \\
3 \\
4\end{array}$ & $\begin{array}{c}918.879 \\
2977.748 \\
6212,832 \\
10624,298\end{array}$ & $\mid \begin{array}{r}910.324 \\
2960.422 \\
6207.430 \\
10600.911\end{array}$ & $\begin{array}{r}13.600 \\
4.460 \\
2.580 \\
2.087\end{array}$ \\
\hline \multicolumn{4}{|c|}{ 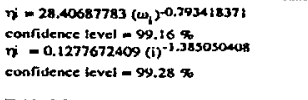 } \\
\hline Teble 3,3 & \multicolumn{2}{|c|}{$0 / 45 / 0$} & \\
\hline \begin{tabular}{|c} 
more No \\
(i)
\end{tabular} & $\omega_{i}$ & $\omega_{\mathrm{d} t i}$ & $\pi_{i}{ }_{0}$ \\
\hline $\begin{array}{l}1 \\
2 \\
3 \\
4\end{array}$ & $\begin{array}{c}916.213 \\
2964.868 \\
6185.951 \\
10578.336\end{array}$ & $\left|\begin{array}{c}910.732 \\
2930.310 \\
6179.211 \\
10520.902\end{array}\right|$ & $\begin{array}{r}14.291 \\
1.762 \\
2.624 \\
2.220\end{array} \mid$ \\
\hline $\begin{array}{l}7 i=28.628 \\
\text { confidence } \\
i=0.134 \\
\text { confidense }\end{array}$ & 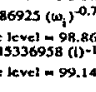 & $\begin{array}{l}7962069350 \\
6 \% \\
1.399030473 \\
4 \%\end{array}$ & \\
\hline
\end{tabular}

Twbie 3.4 $[0 / 90 / 0]$

\begin{tabular}{|c|c|c|c|}
\hline mode No $^{2}$ & $\omega_{i}$ & $\omega_{\mathrm{di}}$ & $n_{1} *$ \\
\hline I & 914.222 & 907.423 & 15.613 \\
\hline 2 & 2962.646 & 2950.310 & 5.342 \\
\hline 3 & 6181.321 & 6168,422 & 2.644 \\
\hline 4 & 10570.424 & 20520.400 & 2.041 \\
\hline
\end{tabular}

$03939\left(\omega_{i}\right)^{-0.291 ;}$

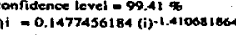

confidense level -98.69

Tntk $3.5 \quad[45 /-45 / 0]$

\begin{tabular}{|c|c|c|c|}
\hline $\begin{array}{c}\text { mode } N_{0} \\
(i)\end{array}$ & $\omega_{i}$ & $\omega_{d i}$ & $\eta_{i} \times$ \\
\hline 1 & 750.560 & 732.410 & 18.462 \\
2 & 2432.292 & 2422.934 & 5.943 \\
3 & 5074.786 & 5052.412 & 3.243 \\
4 & 8628.177 & 8650.932 & 2.594 \\
\hline
\end{tabular}

$n i$ - $39.82579689\left(\omega_{i}\right)^{-0.8223822354}$

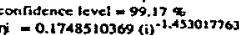
confidence level $=99.11 \%$

Teble $3.6 \quad$ [45/0/45]

\begin{tabular}{|c|c|c|c|}
\hline $\begin{array}{c}\text { mode No } \\
(\mathrm{i})\end{array}$ & $\omega_{i}$ & $\omega_{\mathrm{di}}$ & $\eta_{i} 9$ \\
\hline 1 & 542.069 & 539.702 & 22.301 \\
2 & 1796.813 & 1732.322 & 7.213 \\
3 & 3665.045 & 3651.634 & 3.973 \\
4 & 6267.440 & 6260.124 & 2.981 \\
\hline
\end{tabular}

$\quad i=40.62254216\left(\omega_{i}\right)^{-0.836224538}$

$1216\left(\omega_{i}\right)^{-0.836224338}$ confidence level $-99.49 \%$ confidence levei $=99.68 \%$

Table (4) : The numerical and experimental modal paremetcrs of the first four

Table 4.: [0/0/0]

Table 4.1
\begin{tabular}{|c|c|c|c|}
\hline mode No & {$[0 / 0 / 0]$} \\
\hline (i) & $\omega_{\mathrm{i}}$ & $\omega_{\mathrm{di}}$ & $\eta_{\mathrm{i}} \%$ \\
\hline 1 & 1343.339 & 1320.421 & 12.334 \\
2 & 3702.921 & 3698.343 & 4.222 \\
3 & 7239.203 & 7241.722 & 2.400 \\
4 & 11999.832 & 11972.243 & 2.000 \\
\hline
\end{tabular}

ni -51.28616086 (601) 0.8493262489

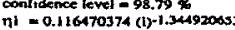

confidenco terel -99.33

Table $4.2 \quad[0 / 30 / 0]$

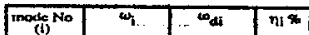

\begin{tabular}{|c|c|c|c|}
\hline 1 & 1333.381 & 1319.734 & 13.426 \\
\hline
\end{tabular}

\begin{tabular}{lll|l|l|}
2 & 3675.505 & 3654.432 & 4.400 \\
\hline
\end{tabular}

\begin{tabular}{|l|l|l|l|l|}
1 & 11910.975 & 11812.326 & 2.083 \\
\hline
\end{tabular}

$n i=63.64979558\left(\omega_{1}\right) 0.069594348$

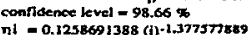

confidenoe kevel in $99.23 x$

Tobic 4 S.S [0/45/0]

\begin{tabular}{|c|c|c|c|}
\hline $\begin{array}{c}\text { modede } \\
\text { (i) }\end{array}$ & $\omega_{\mathrm{i}}$ & $\omega_{\mathrm{di}}$ & $\eta_{11} \%$ \\
\hline 1 & 1329.512 & 1320.462 & 14.032 \\
2 & 3659.607 & 3640.321 & 4.693 \\
3 & 7174.283 & 7163.522 & 2.620 \\
4 & 11859.447 & 11850.231 & 2.133 \\
\hline
\end{tabular}

$\eta i=73.42085231\left(\omega_{i}\right)-0.862331201$

confidence level -98.83
$\eta i=0.1328192739(i)-4.396000133$

confiscike level $=99.35 \%$

$\omega_{i}=$ lirequeney, (rad / scci)

"did $\sim$ Dumpred frequeincy,(rad $/ \mathrm{sec}$

Table 4A 10/90/0)

\begin{tabular}{|c|c|c|c|}
\hline mode $\left.\mathrm{NO}^{(}\right)$ & $w_{i}$ & $w_{\mathrm{di}}$ & $n_{i} \%$ \\
\hline 1 & 1326.623 & 1318.420 & 15.229 \\
2 & 3636.864 & 3532.326 & 5.239 \\
3 & 7168.913 & 7139.463 & 2640 \\
4 & 11850.577 & 11820.234 & 2.392 \\
\hline
\end{tabular}

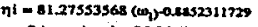

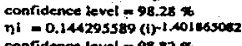
confidence level -98.82

Troble 4.S [45/-As/O]

\begin{tabular}{|c|c|c|c|}
\hline $\operatorname{modn}_{\text {(i) }}$ No & $\omega_{i}$ & $\omega_{\mathrm{dI}}$ & $n_{i} \%$ \\
\hline 1 & $\begin{array}{l}1089.134 \\
3002.236\end{array}$ & $\begin{array}{l}1009.923 \\
3000.226\end{array}$ & 17.934 \\
\hline 3 & S8RSSS86 & 5880.421 & $\mid \begin{array}{l}3.712 \\
2884\end{array}$ \\
\hline 4 & 9729.160 & 9720.262 & 2.548 \\
\hline
\end{tabular}

71 - 107.6262435 (wij) $0.92 \mathrm{ma367435}$ -

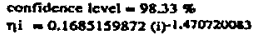
confidence kevel $\mathbf{m} 98.90 \%$

Tuble 4.6 [45/0/45]

\begin{tabular}{|c|c|c|c|}
\hline $\begin{array}{c}\text { mode } \\
(i)\end{array}$ & $\omega_{i}$ & $\omega_{d 1}$ & $\eta_{i}$ \\
\hline 1 & 786.593 & 780.932 & 21.952 \\
2 & 2168.230 & 2153.462 & 6.933 \\
3 & 4250.630 & 4230.262 & 3.800 \\
4 & 7026.471 & 7019.942 & 2.803 \\
\hline
\end{tabular}
ri $=117.4189045\left(\omega_{i}\right)-0.9534623338$ conntidenee level = $99.32 \pi$
$\eta i=0.210201369$ (i)
$\eta$. cunfidense level $=99.71 \%$ 


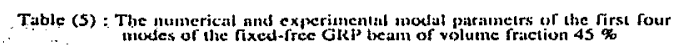

\begin{tabular}{|c|c|c|c|c|c|c|c|}
\hline \multirow{2}{*}{$\begin{array}{l}\text { Tabic S.l } \\
\text { monkiko } \\
(i)\end{array}$} & \multicolumn{3}{|c|}{$10 / 0 /$ 이 } & \multirow{2}{*}{ 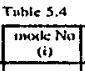 } & \multicolumn{2}{|c|}{ [0/ 190$) / 0\}$} & \multirow[b]{2}{*}{$n_{i} x_{0}$} \\
\hline & $4 x$ & wali & $n_{i} \omega_{n}$ & & कां & tindi & \\
\hline 9 & $299.102-1$ & 245.310 & 10.160 & ' & 294.631 & $27(1.46(x)$ & 11.432 \\
\hline$s^{2}$ & 1873.816 & |KSY,K2.3] & $3,6,32 \mid$ & 2 & $1845,43,3$ & IH22.124 & $4.3 \% 6$ \\
\hline 3 & 5246.742 & 5152.212 & 2.250 & 3 & 5170.0609 & 4013,451 & 2.430 \\
\hline 4 & t0281.522 & $1(x \times 240.5310$ & $\mid .50 \mathrm{t}$ & 4 & 10136.272 & 9452.3661 & 1.7124 \\
\hline \multicolumn{4}{|c|}{ 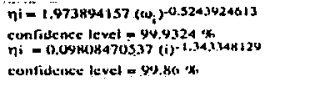 } & \multicolumn{4}{|c|}{ 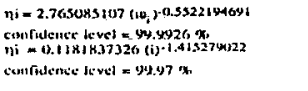 } \\
\hline Tulbe 3.2 & \multicolumn{3}{|c|}{$10130 / 01$} & Tulbles: & \multicolumn{3}{|c|}{$|45 / .45 / 0|$} \\
\hline 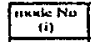 & wit & waxki & 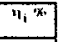 & \begin{tabular}{|c|} 
munkene \\
(i)
\end{tabular} & wisi & bist & \\
\hline 1 & 256.322 & $2 \times 9: \ldots 127$ & $119.8 \%$ & 1 & 230.1043 & $213.162 x$ & 15.294 \\
\hline 2 & 1857.310 & 1847.256 & $3.9 \%$ & 2 & $14,45,+413.3$ & $14,32.560$ & 5.712 \\
\hline 3 & $51 \%, 70 \times 1$ & $49 \times 3.349$ & 2.3 .314 & 3 & $\sec 27.170$ & $4(121.239)$ & $2 \cdot-x 12$ \\
\hline 4 & 10198,479 & $|(x) 327.4 \mathrm{~cm}|$ & 1.63014 & 4 & 79.6 .84 .4 & $\mid 7929.3 \times 18$ & $2.2 \mathrm{vH}$ \\
\hline \multicolumn{4}{|c|}{ 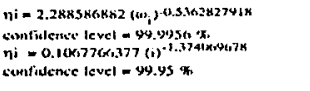 } & \multicolumn{4}{|c|}{ 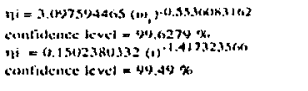 } \\
\hline Tutise 5.3 & \multicolumn{3}{|c|}{$[0 / 45 / 0]$} & Titate 3.0 & \multicolumn{3}{|c|}{$[45 / 0 / 4.5]$} \\
\hline $\operatorname{moxk}_{(i)} \mathrm{No}^{2}$ & aiv & contic & $n x$ & 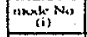 & ioi & unti & $3 i * x$ \\
\hline 1 & $29-1.426$ & $2 k 2,742$ & $\{1,1,2\}$ & 1 & 341.529 & $1.3 \times .2 \times 0$ & 20.9210 \\
\hline 2 & $1 \times 4 \times .2 \times 1$ & $|x \leq 5, \times 23|$ & $4: 2=2$ & $=$ & $x \times(0, y(x)$ & $8+1.947$ & 7.402 \\
\hline 3 & 5175.234 & 4835.1300 & 2.3 .48 & 3 & 2483.511 & 2475.575 & 3.xus \\
\hline 4 & $10241.3 \%$ & 10015.397 & $1.6 \times 2=$ &. & $A h\left(x_{0},\{1,1) 1\right.$ & $4 N 6,3.1 \% 5$ & 2.642 \\
\hline \multicolumn{4}{|c|}{ 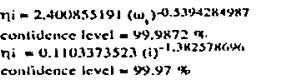 } & \multicolumn{4}{|c|}{ 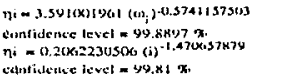 } \\
\hline
\end{tabular}

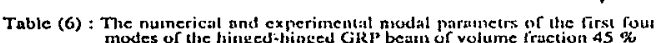

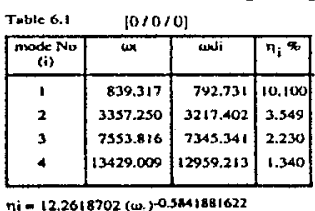

7i $\left.=12.2618702\left(\omega_{i}\right)-0.544\right) 1881622$

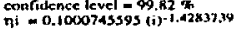

confidence ievel $=\$ 9.82 \%$

Thate 6.2 $[0 / 30 / 0]$

\begin{tabular}{|c|c|c|c|}
\hline $\operatorname{moxe}_{(i)}$ No & $\omega \pi$ & andi & $n_{i} \%$ \\
\hline 1 & 831.429 & 792.423 & 10.507 \\
\hline 2 & 3327.677 & 3304.214 & 3.820 \\
\hline 3 & 7481.863 & 72.04 .232 & 2.300 \\
\hline 4 & 13310.742 & 12364.2 .35 & 1.615 \\
\hline $\begin{array}{l}\text { ni }-12.7 \\
\text { canfrack } \\
\eta \mathrm{i}-0.1 \\
\text { comfiden }\end{array}$ & $3(x)=8$ & 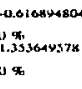 & \\
\hline
\end{tabular}

Table 6.3 fo/ $45 / 01$

\begin{tabular}{|c|c|c|c|}
\hline${ }_{\text {mole }}^{\text {No }}$ & $\omega \boldsymbol{w}^{\mathrm{i}}$ & cunti & $n_{1} \%$ \\
\hline 1 & 827.870 & 748.024 & $11.1(x) \mid$ \\
\hline 2 & $.3311 .5(x)$ & $33(x) .423$ & -4.22110 \\
\hline 3 & $7450.86,5$ & 7422,372 & 2.340 \\
\hline 4 & $13245.9 \times 3$ & $|12932.421|$ & 1.6501 \\
\hline \multicolumn{4}{|c|}{ 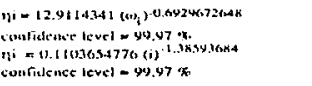 } \\
\hline
\end{tabular}

Tuble $6.5 \quad$ [45/.45/0]

\begin{tabular}{|c|c|c|c|}
\hline $\begin{array}{c}\text { Imxde } \\
\text { (i) }\end{array}$ & \multicolumn{1}{c|}{ Noi } & wesi & \\
\hline 1 & 647.425 & 623.231 & 14.621 \\
2 & 2589.677 & 2504.921 & 5.622 \\
3 & 5826.782 & $3 \times 10.234$ & 2.731 \\
4 & 10356.717 & 9978.721 & 2.200 \\
\hline
\end{tabular}

ni $=14.1446 / 8289\left(\omega_{i}\right) \cdot 0.7075073403$ confidcunce level 299.54 th $\eta_{11}=0.1+50 \times 3 \times 3529(1)$

Tulile $0.6, \quad[15 / 0 / 45]$

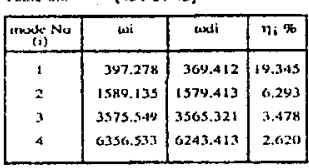

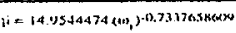

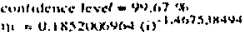

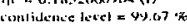

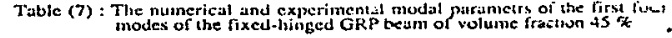

\begin{tabular}{|c|c|c|c|}
\hline \multirow{2}{*}{$\begin{array}{l}\text { Tuble } 7.1 \\
{\left[\begin{array}{c}\text { mude } \\
\text { (i) }\end{array}\right.} \\
\end{array}$} & \multicolumn{2}{|c|}{$0 / 0 / 0$} & \multirow[b]{2}{*}{$n_{i}$} \\
\hline & \begin{tabular}{l|l} 
win \\
\end{tabular} & $4 \times x^{2}$ & \\
\hline 1 & 1311.173 & 1210.233 & 10.070 \\
\hline 2 & 4249.018 & 4196.204 & $3.4(x)$ \\
\hline 3 & k865.2+2 & 7672,410 & 2.250 \\
\hline 4 & $15200(n) 2] 1$ & 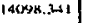 & $1.2 \%$ \\
\hline \multicolumn{4}{|c|}{ 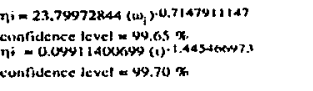 } \\
\hline Tuthe 7.2 & \multicolumn{2}{|c|}{$[0 / 30 / 0]$} & \\
\hline $\begin{array}{c}\text { moverc No } \\
\text { (i) }\end{array}$ & ini & sindin & $n, n_{0}$ \\
\hline 1 & 1249.6 .1 .32 & 1136.235 & $\{16.3 .37\}$ \\
\hline 2 & $+22+1.560$ & $3344,1+4 \mid$ & 3.970 \\
\hline 3 & 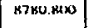 & $75 \times 6.21 .3$ & 2.28 .1 \\
\hline 4 & $15026.5 \% 0$ & $\mid 44+1.3=1$ & $1,(x *)$ \\
\hline \multicolumn{4}{|c|}{ 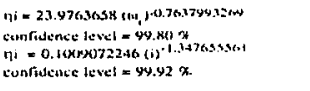 } \\
\hline Tubic 7.3 & \multicolumn{2}{|c|}{$10 / 45101$} & \\
\hline \begin{tabular}{|c|}
$\operatorname{mank} N \mathrm{No}$ \\
$(\mathrm{i})$
\end{tabular} & wi & (4) & $n i$ \\
\hline 1 & 1243.291 & 1021.4 & $|(1.1 .40,0)|$ \\
\hline 2 & 4121.6160 & $|31, \times 8.20 ;|$ & .2 .215 \\
\hline 3 & 8744.418 & | $6.589 .523 \mid$ & 2.343 \\
\hline 4 & 14953.473 & {$[1+5(x) .231]$} & 1.(rnit) \\
\hline \multicolumn{4}{|c|}{ 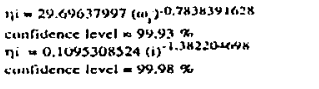 } \\
\hline
\end{tabular}

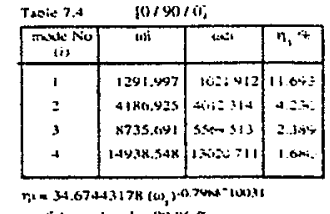

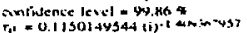

ivitidemer Icecl a (y). 95 \&

TAsic 7.3 14.5/-45io:

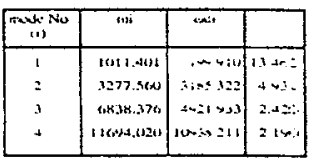

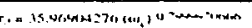

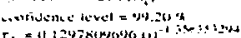

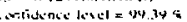

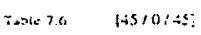

\begin{tabular}{|c|c|c|c|}
\hline 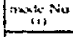 & (1ii & Nat & 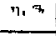 \\
\hline I & ${ }_{1020} 20,24$ & $\therefore-4: 1$ & $\sin$ in. \\
\hline 2 & $20011.24 x$ & $19 x+2=1$ & 60140 \\
\hline 3 & $419 \mathrm{C}_{1} 3 \mathrm{HS}$ & $=4: 20061$ & 3 linge \\
\hline 4 & $2175,0,360$ & $x: 2:+1+4$ & $=\dot{*}$ \\
\hline
\end{tabular}

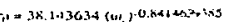

anfidencec lavel $=44.22 \pi$ caxilideine level $=49.41$ \%

$n_{i}=$ Dumping $\left(x_{0}\right)$ (i)

Table (8): The numerical and experimenual neutal paramers of the first foew

Tubie 8,1
\begin{tabular}{|c|c|c|c|}
\hline $\begin{array}{c}\text { mode No } \\
\text { (i) }\end{array}$ & wi & wedi & $n_{i} x$ \\
\hline 1 & 1902.637 & 1824.301 & 10.044 \\
2 & 5244.665 & 5123.914 & 3.239 \\
3 & 10281.646 & 10391.313 & 2.199 \\
4 & 16996.086 & 15992.412 & 1.290 \\
\hline
\end{tabular}

ni $=53.0786004 !\left(w_{1}\right)-0.8496400376$ confidcrece levei $=98.30 \%$ confidence bevei $99.54 \%$

Tuble 8.2 $\left[0 / 30 / 0_{1}\right.$

\begin{tabular}{|c|c|c|c|}
\hline $\begin{array}{c}\text { mode No } \\
\text { (i) }\end{array}$ & 4* & cundi & $\eta_{i} \%$ \\
\hline 1 & 1885.889 & 1693.621 & 10.200 \\
\hline 2 & 3198.406 & 3187.322 & 3.741 \\
\hline 3 & 10183.711 & $\mid 10662.911$ & 2.270 \\
\hline 4 & 16846,403 & |:5932.440 & $1.5 \% 0$ \\
\hline
\end{tabular}

\begin{tabular}{|c|c|c|c|}
\hline & \multicolumn{3}{|c|}{$[0 / 90 / 0]$} \\
\hline 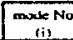 & wi & $\omega$ & $n_{i} *$ \\
\hline 1 & 1874.811 & 1003.212 & 111320 \\
\hline 2 & 5168.022 & 5100.333 & 4.206 \\
\hline 3 & 10131.396 & 10123012 & 2.330 \\
\hline 4 & 10747.732 & $15932+400$ & $1.6 \mathrm{NV}$ \\
\hline
\end{tabular}

$\eta_{i}=84.68154885\left(\omega_{i}\right)-0.803131142$ confivente levet -99.200 coafutence ievel $=99.78$ x

[145/-45/0]

\begin{tabular}{|c|c|c|c|}
\hline $\operatorname{modk}_{(1)} \mathrm{No}$ & $\omega i$ & $\infty$ & \\
\hline t & 1467.639 & 1200224 & 12.35e \\
\hline ? & 4045.370 & $402 \times 914$ & 4.482 \\
\hline 3 & 7930.9447 & 2003510 & 2.500 \\
\hline 4 & אי110.2410 & $1=14 \times 0.023$ & \begin{tabular}{|l|}
1.970 \\
\end{tabular} \\
\hline
\end{tabular}

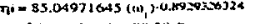

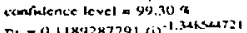
$n_{1}=0.61 \times 9287291\left(i^{-1}\right)^{-1.3 n}$

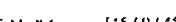

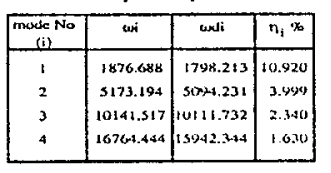

$n i=74.57958705\{(4,3) .0 .8714420233$ ciufrivenie level $=$ Wy. $73 x$. confidence level $=99.95$.

ai, - Frequency, (rus / xec)

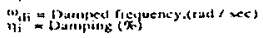

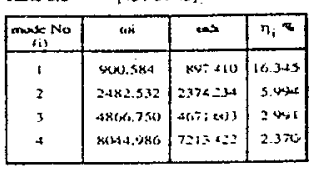

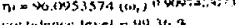

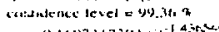

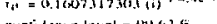

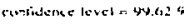




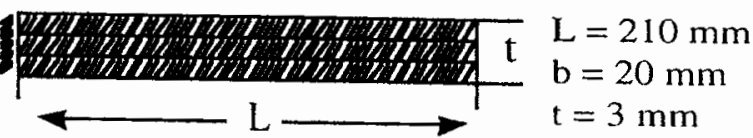

Fig. (1 a) : 3-layer beam model.

1. Beam models

2. Impact hammer with built-in forec transducer.

3. Piezoclectric-accelerometcr.

4. Charge amplifier.

5. Conditioning amplifier.

6. Dual-channel signal analyzer.

7. Computer.

8. Printer.
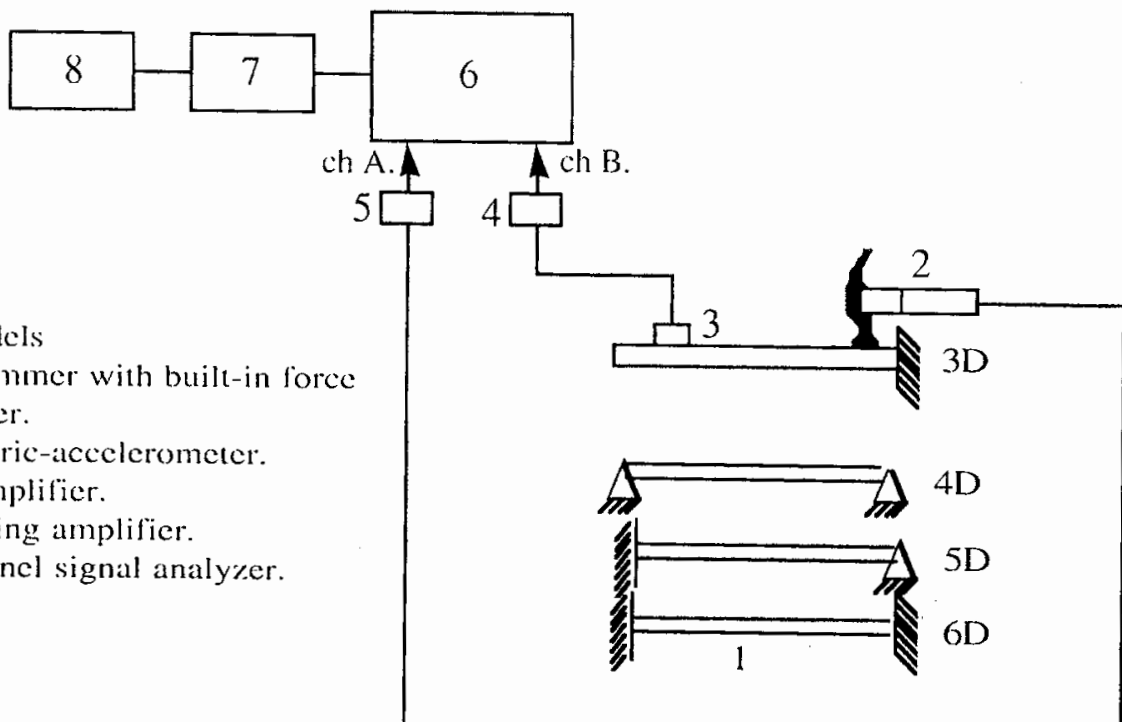

(Fig. 1 b) : Schematic block diagram of the measuring circuit. 


\begin{tabular}{|llllll|}
\hline 0 & {$[0 / 0 / 0]$} & $\Delta$ & {$[0 / 30 / 0]$} & 0 & {$[0 / 45 / 0]$} \\
0 & {$[0 / 90 / 0]$} & - & {$[45 /-45 / 0]$} & $\cdots$ & {$[45 / 0 / 45]$} \\
\hline
\end{tabular}

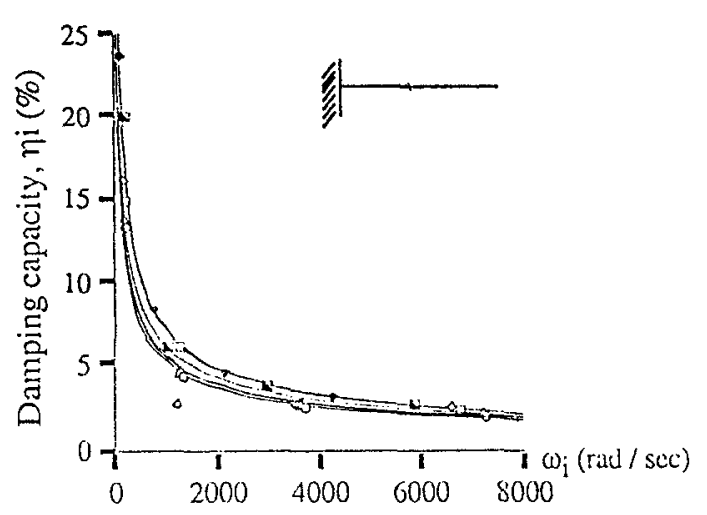

Ref: Tables 1.1 to 1.6

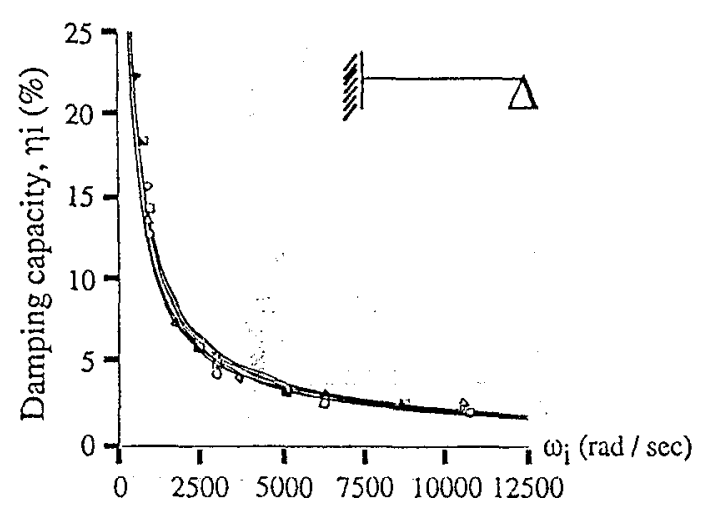

Ref. Tables 3.1 to 3.6

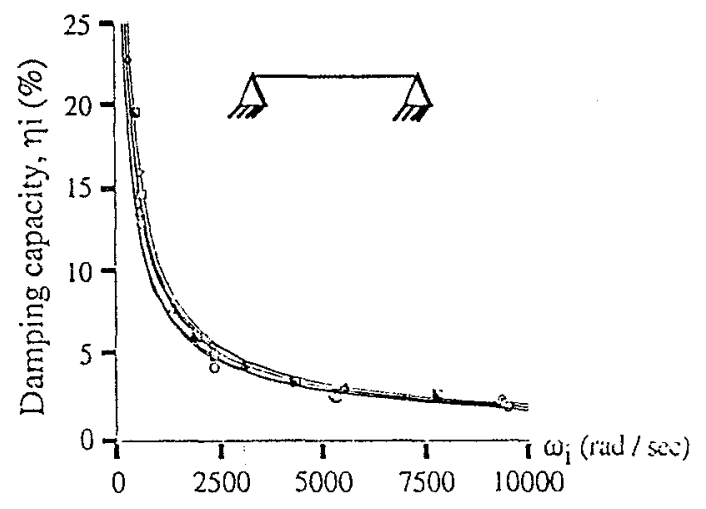

Ref. Tables 2.1 to 2.6

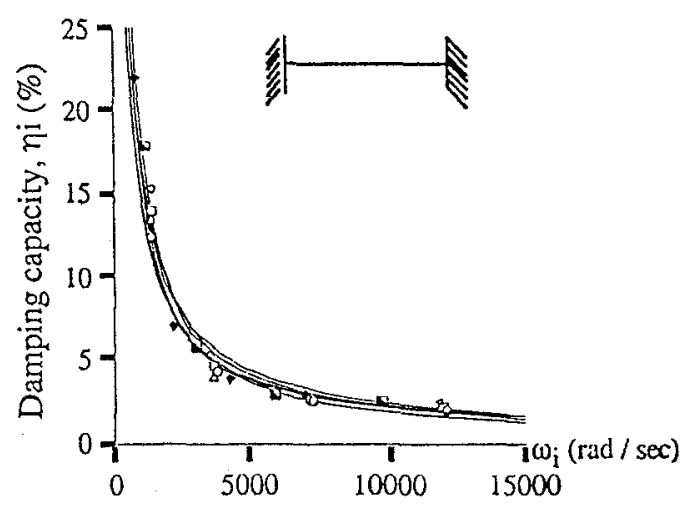

Ref. Tables 4.1 to 4.6

Fig. (2) : Quasihyperbolic relationship relating damping capacities $\eta \mathbf{i}$ with natural frequencies, $\omega_{i}$ for LBC of various orientations for different types of fixations at $V_{f}=15 \%$. 


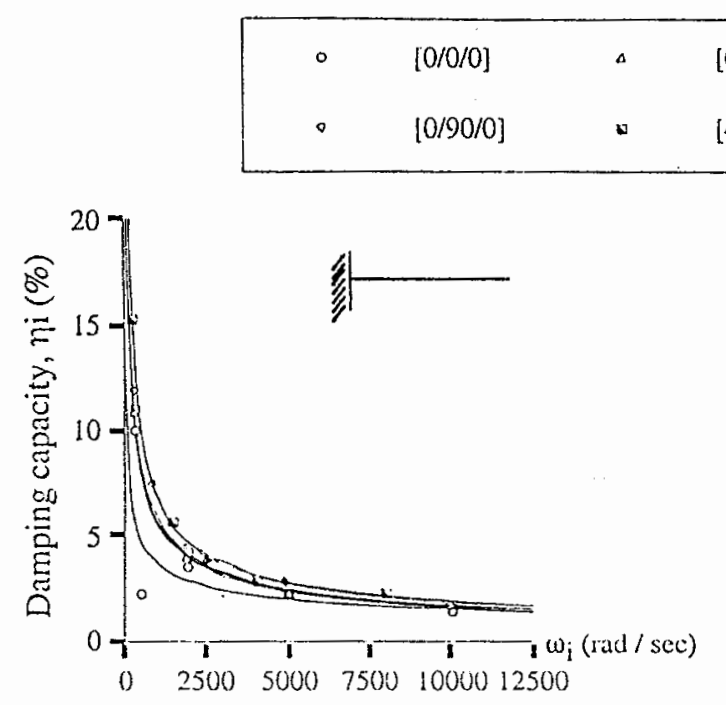

Ref. Tables 5.1 to 5.6

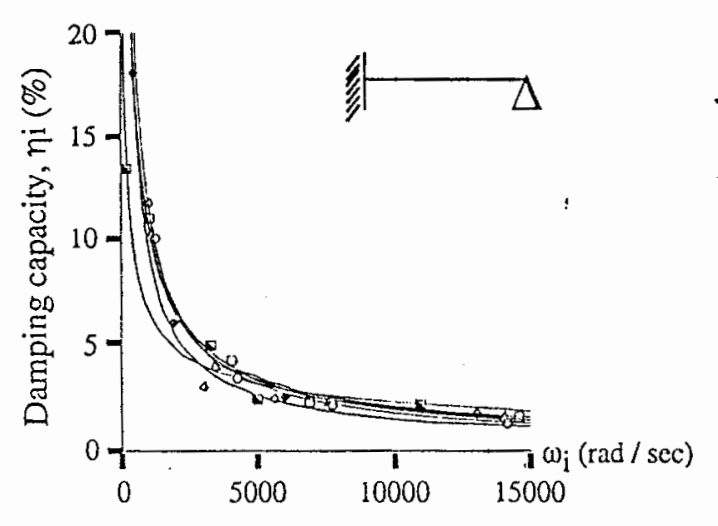

Ref. Tables 7.1 to 7.6

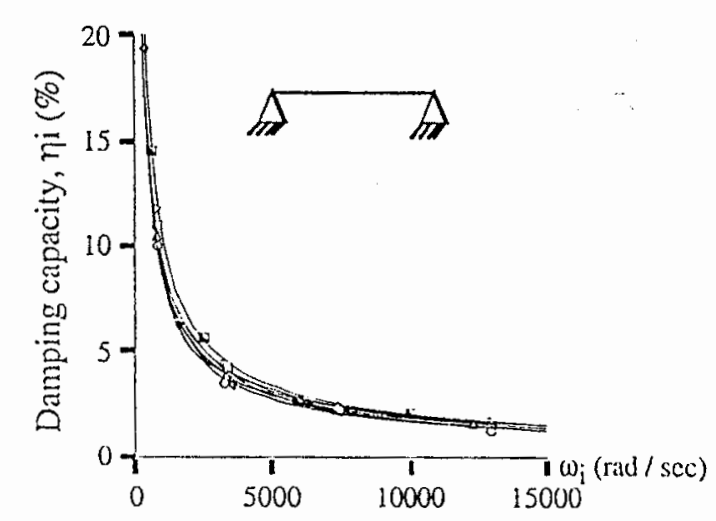

Ref. Tables 6.1 to 6.6

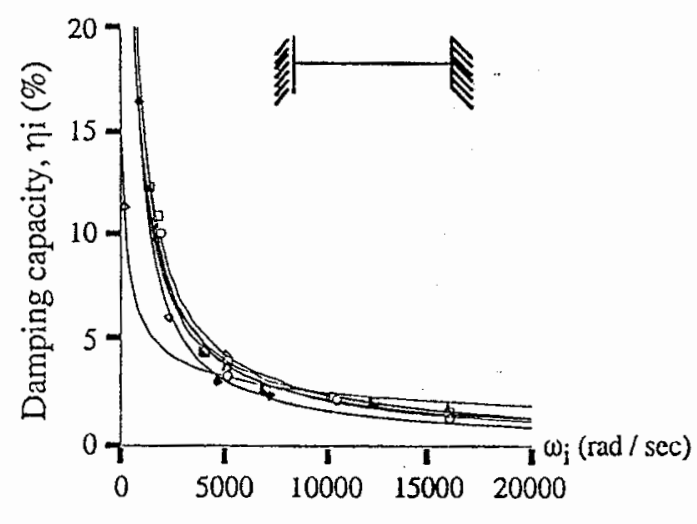

Ref. Tables 8.1 to 8.6

Fig. (3): Quasihyperbolic relationship relating damping capacities $\eta \mathrm{i}$ with natural frequencies, $\omega_{i}$ for $L B C$ of various orientations for different types of fixations at $\mathrm{V}_{\mathrm{f}}=45 \%$. 


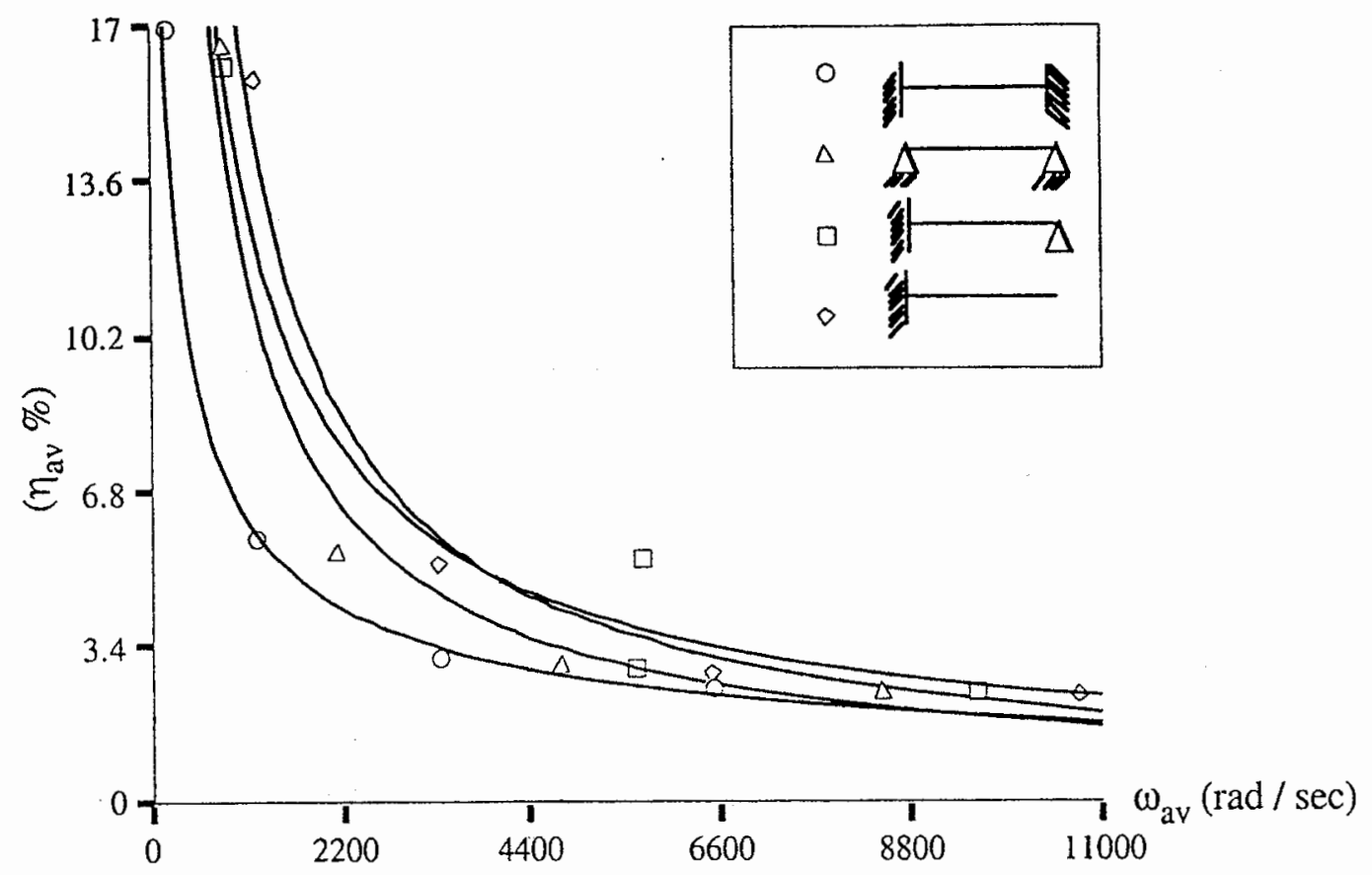

Fig. (4a) : Generalized quasihyperbolic relations between damping capacities, $\eta_{\mathrm{av}}$ and natural frequencies $\omega_{\mathrm{av}}$ for various types of fixations at $\mathrm{V}_{\mathrm{f}}=15 \%$.

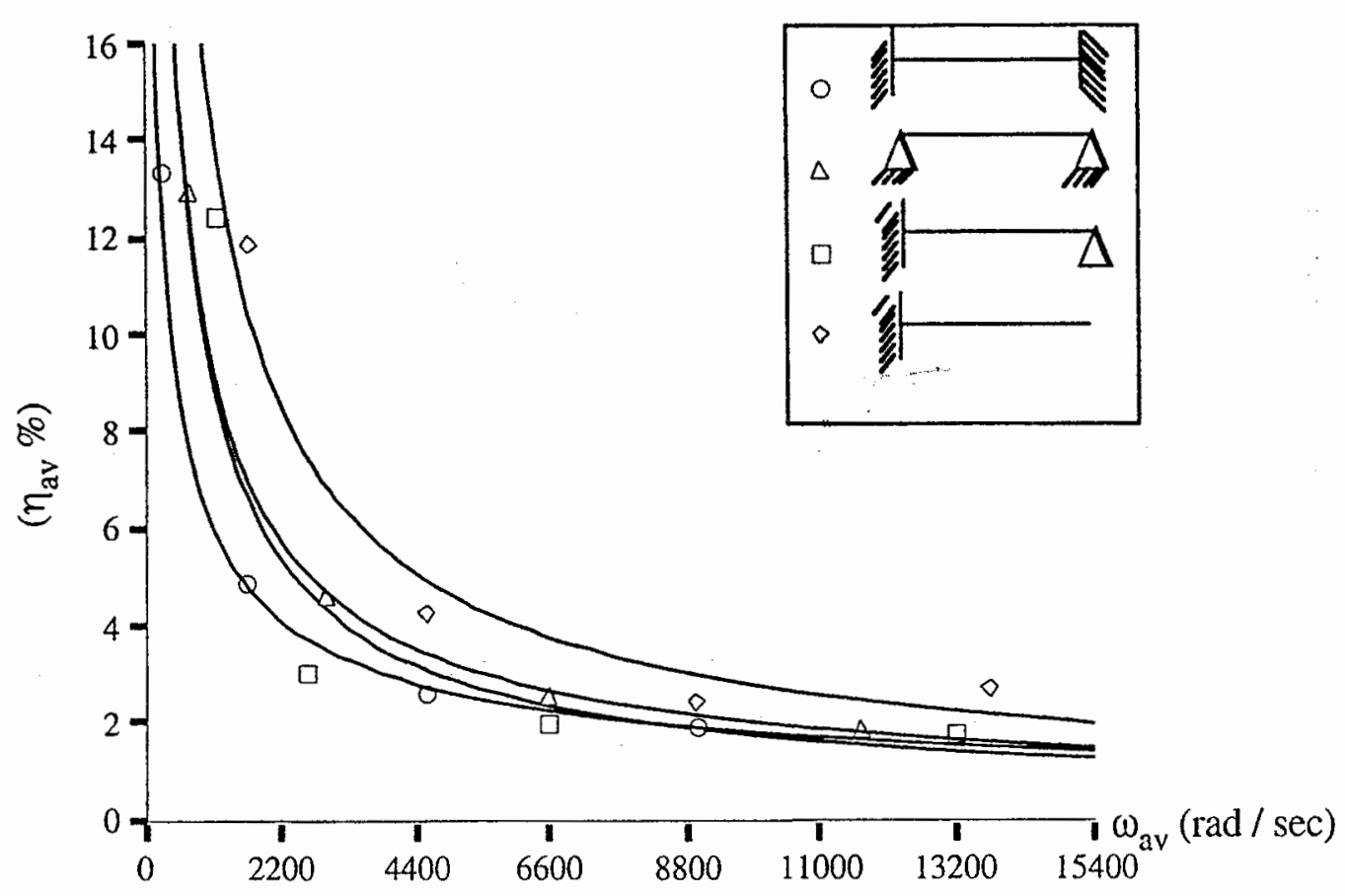

Fig. (4b) : Generalized quasihyperbolic relations between damping capacities, $\eta_{\mathrm{av}}$ and natural frequencies $\omega_{\mathrm{av}}$ for various types of fixations at $V_{\mathrm{f}}=45 \%$. 


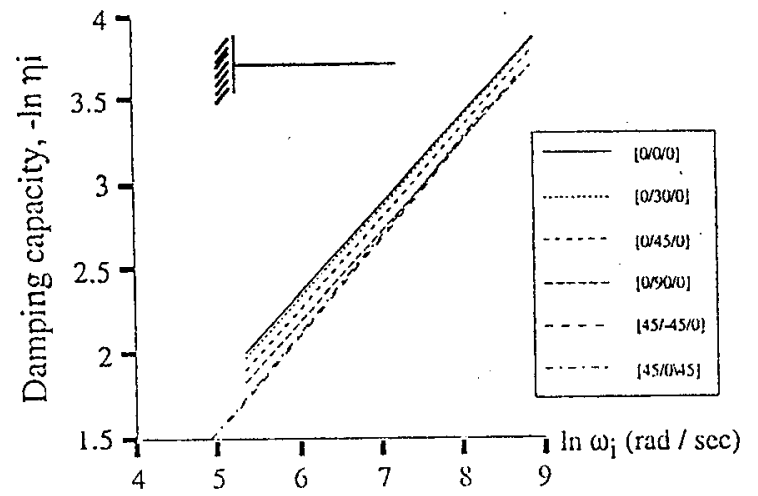

Ref. Tables 1.1 to 1.6

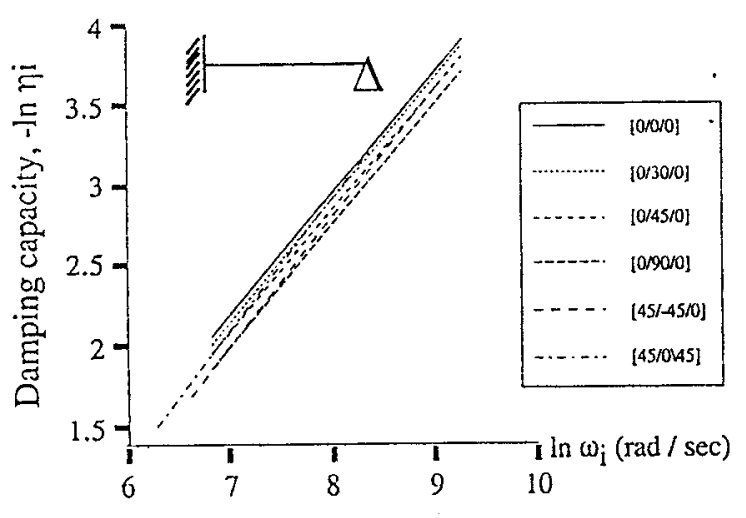

Ref. Tables 3.1 to 3.6
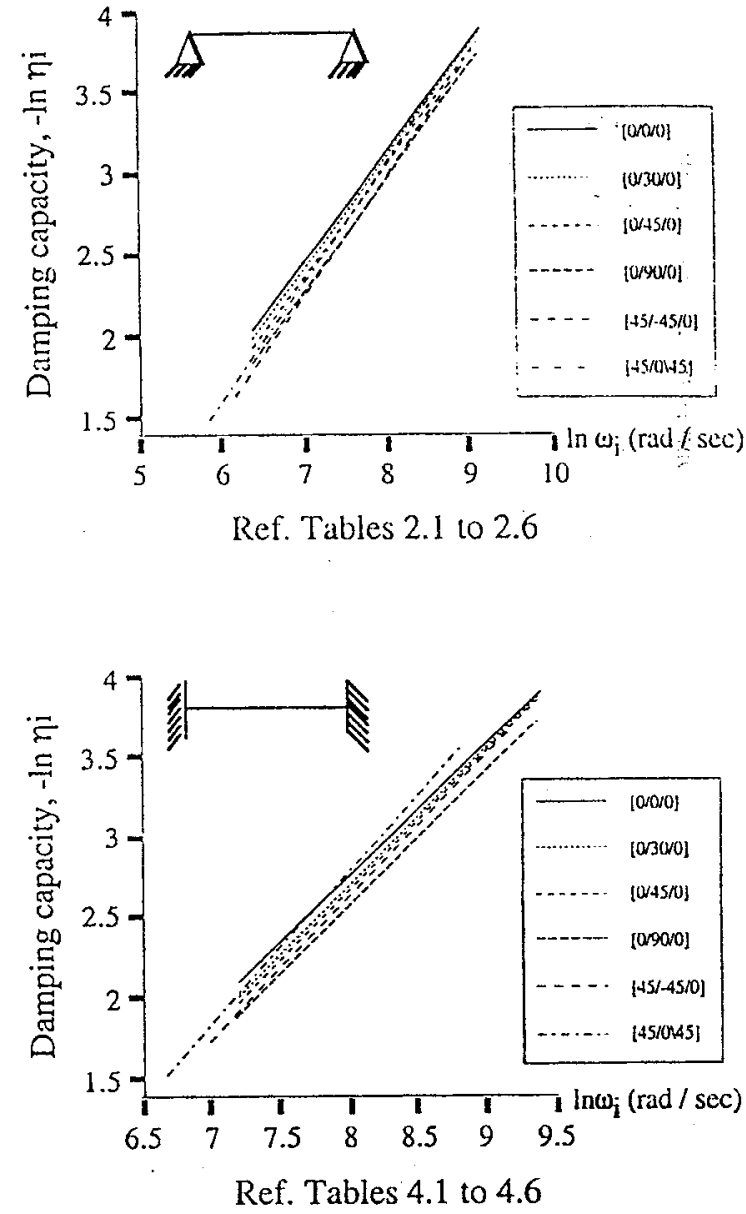

Fig. (5) : Logarithmic forms relating damping capacities, $\eta_{i}$ with natural frequencies, $\omega_{\mathrm{i}}$ for $\mathrm{LCB}$ of various orientations for different types of fixations at $\mathrm{Vf}=$ $15 \%$. 

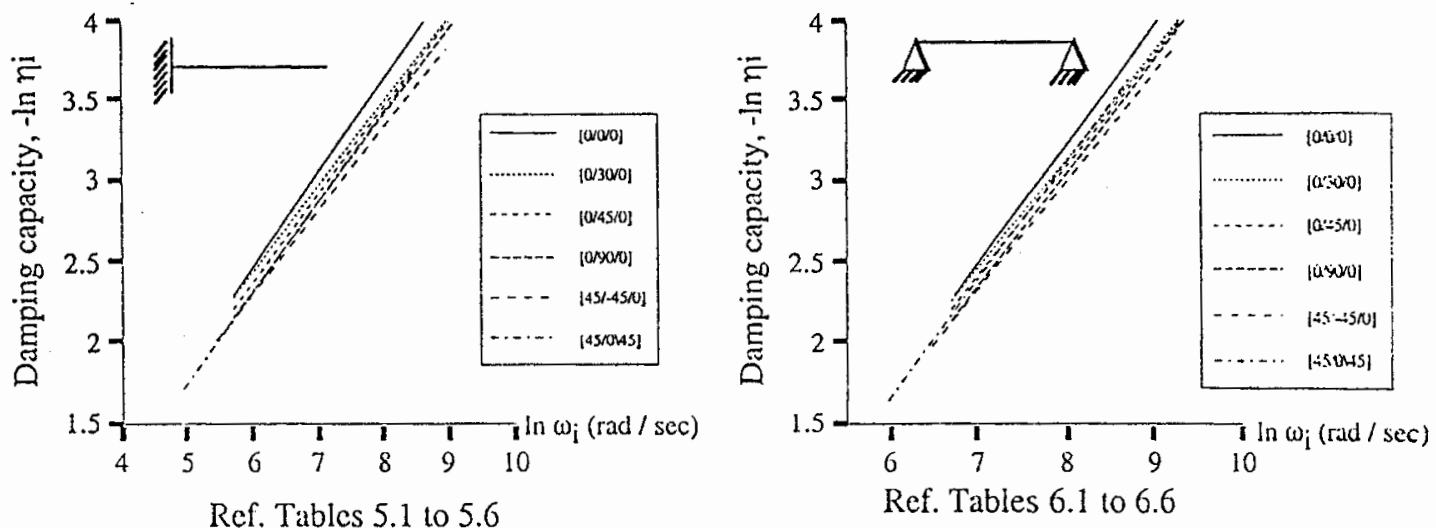

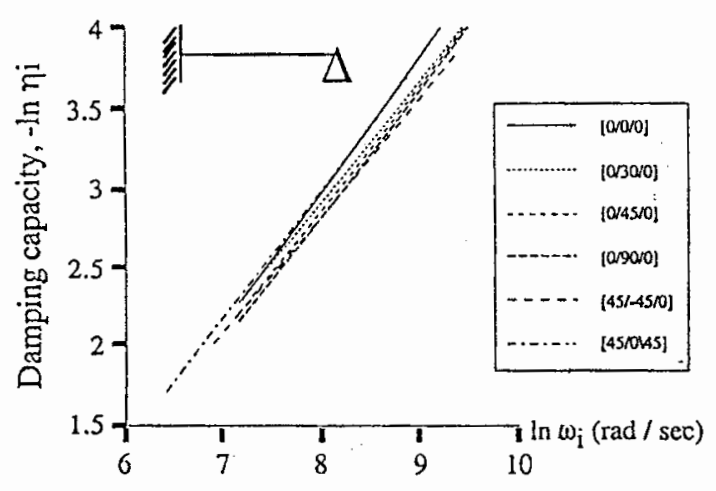

Ref. Tables 7.1 to 7.6

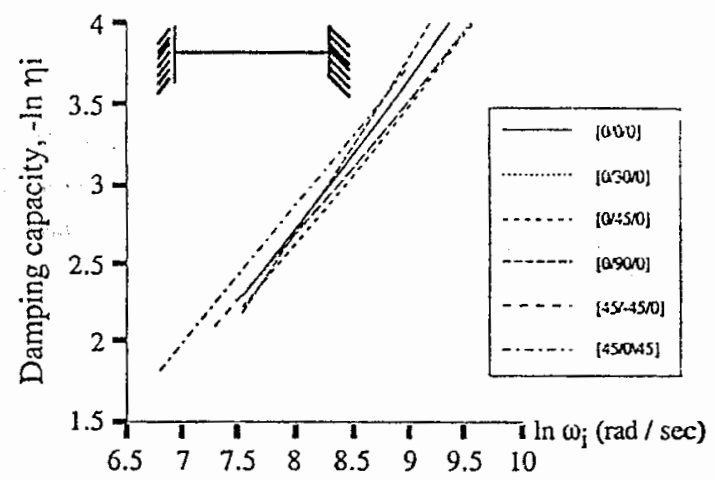

Ref. Tables 8.1 to 8.6

Fig. (6) : Logarithmic forms relating damping capacities, $\eta i$ with natural frequencies, $\omega_{i}$ for $L C B$ of various orientations for different types of fixations at $V_{f}=$ $45 \%$. 


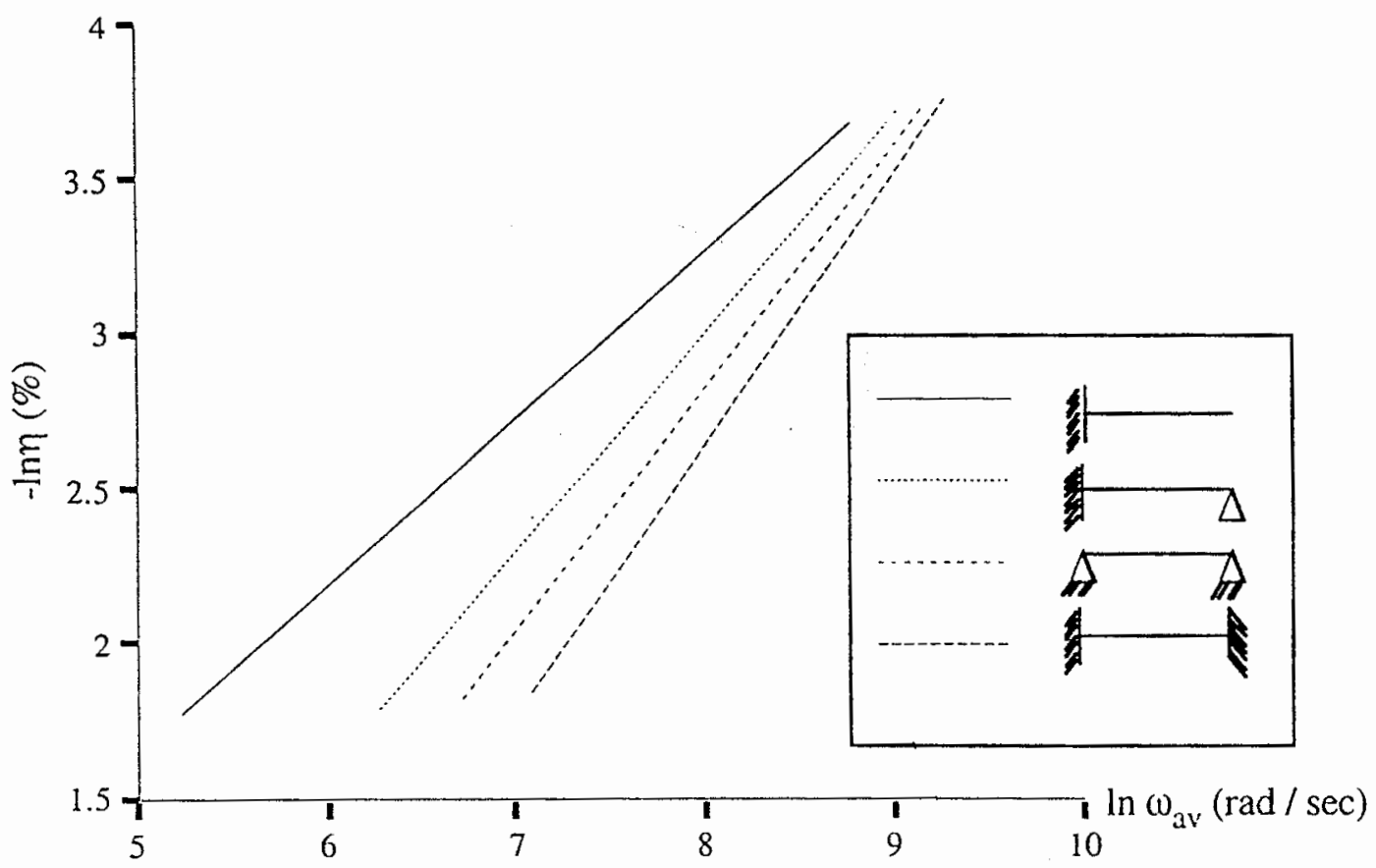

Fig. (7) : Generalized logarthmic quasilinear forms relating damping capacities, $\eta_{i}$ with natural frequencies $\omega_{i}$ for various types fixations at $V_{f}=15 \%$ (ref. Table 9).

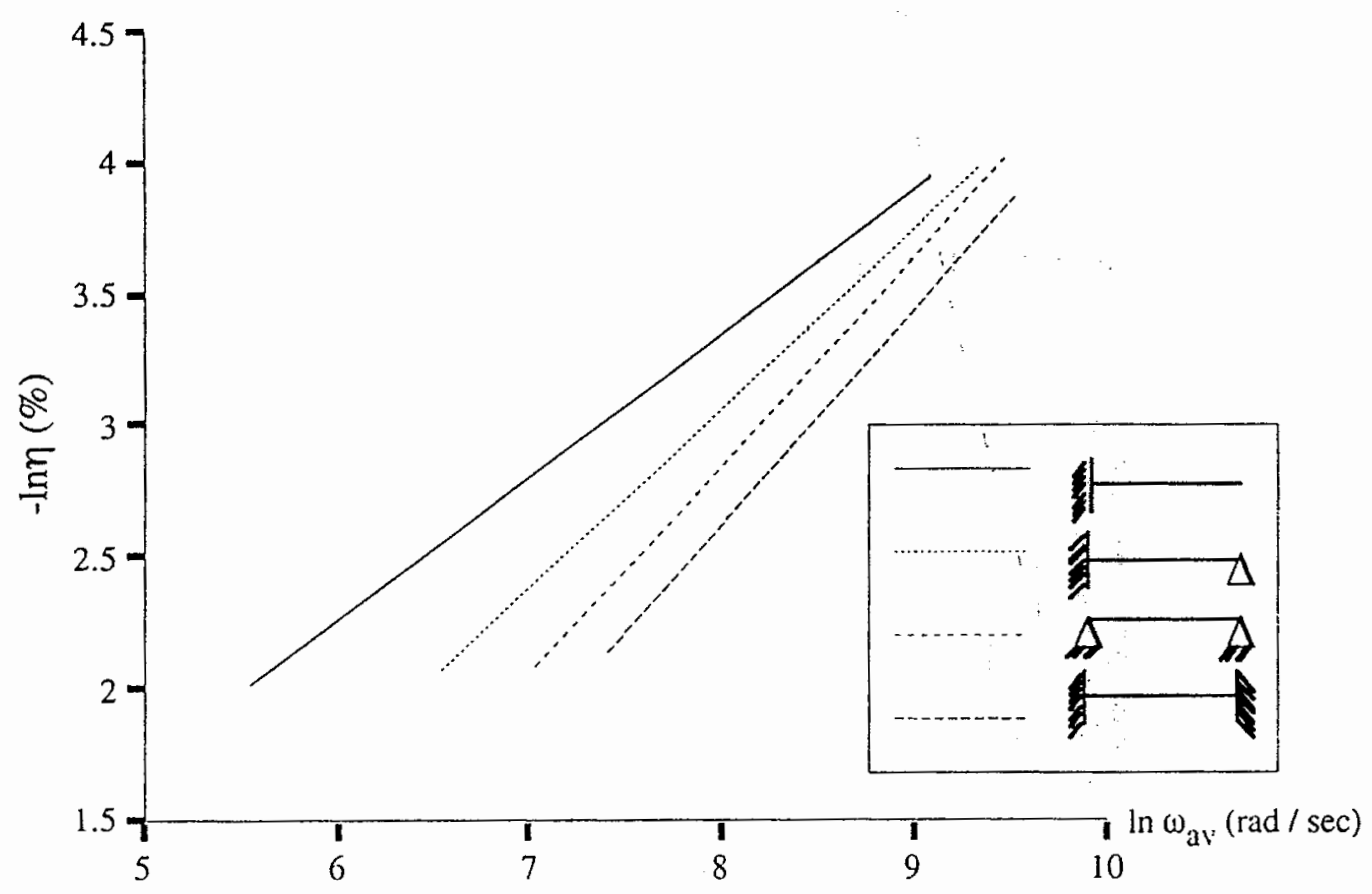

Fig. (8) : Generalized logarithmic quasilinear forms relating damping capacities, $\eta$ with natural frequencies $\omega_{i}$ for various types of fixations at $V_{f}=45 \%$ (ref. Table 9). 


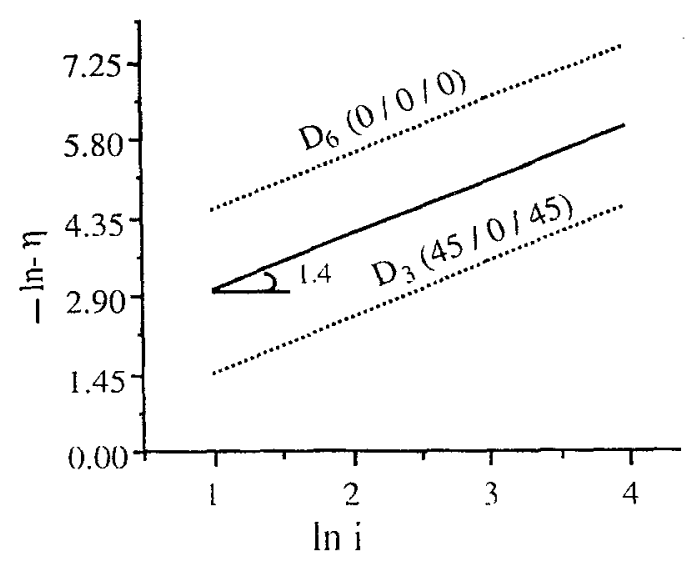

Fig. (9) : Logarithmic representation of dmping loss factors in various natural modes.

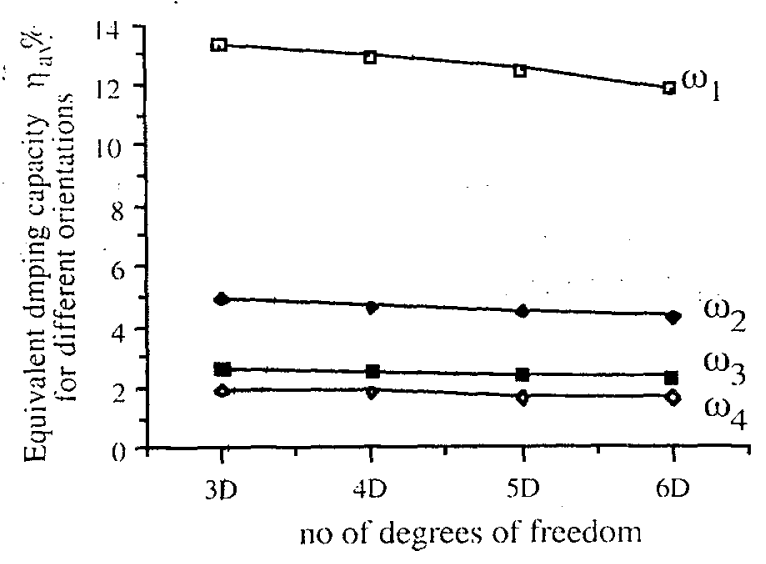

Fig. (10) : Equivalent damping capacity $\eta_{\mathrm{cq}} \%$ for various degree of constraint (D) at $\mathrm{V}_{\mathrm{p}}=$ $45 \%$.

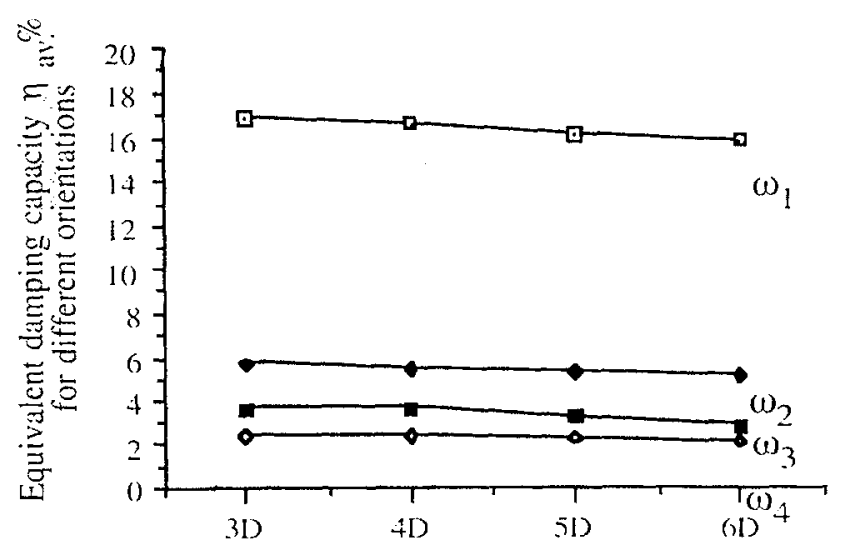

no. of degrees of treedom

Fig. (11) : Equivalent damping capacity $\eta_{\mathrm{eq}} \%$ for the degree of constraint (D) it $V_{i}=$ $15 \%$. 


\section{نهوذج معدل للسلوك الإخمادى فى المنشآت المهتزة المصنعة من ألياف الزجاج

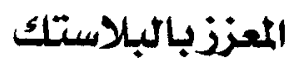

د. أحملد ماهر ، دـ. فوقية رمضان

ملخص البحث

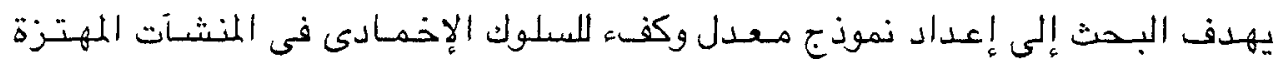
المصنعة من ألياف الزجاج المعزز بالبالاستل وذللك بتحسين خصائص التقارب بين القياسات

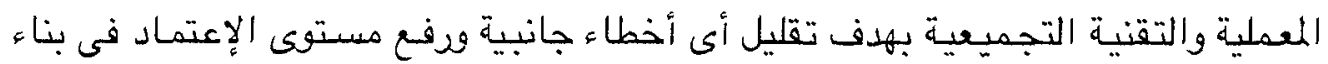
النموذج المعدل وذلك بحسابات عوامل الوزن (a a a مع مراعاة مدى واسع من الترددات -

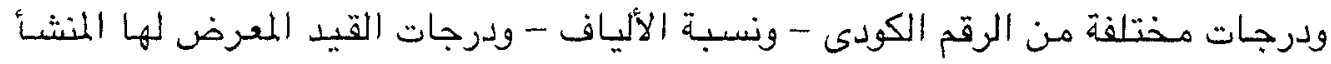

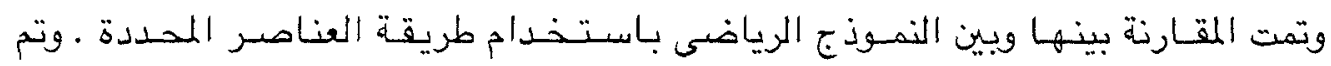
التوصل إلى تمثيل السلوك الإخمادى لألياف الزجاج المعزز بالبلاستك بالإخماد ذو الكتلة

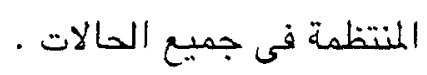

وتم التوصل أيضاً إلى أن العلاقة بين معامل بالإخماد والترددات الطبيعية للمنشـأ قطع المع زائدى المقطع .

وتم إنثـاء علاقة لوغاريتمية يسـهل التعامل معهـا قبل وبعد قيم الترددات التى تمت .

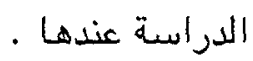

